\title{
تطبيق طريقة سوروكان في تعليم كتب التراث
}

\author{
Amirul Mukminin ${ }^{1}$, Khoirul Anwar ${ }^{2}$, Aisyatul Hanun ${ }^{3}$ \\ Universitas Ibrahimy, Situbondo, Indonesia \\ 1* $\underline{\text { mora.mukmin@gmail.com, }}, \underline{2}$ mas_anwar78@yahoo.co.id, ${ }^{3}$ hanun89@gmail.com
}

\begin{abstract}
This research started from learning at Al-Badriyah Islamic Boarding School which since established applying Sorogan Method in some lesson kitab turats, the students and the graduates proved to have the ability to understand the Qur'an and religious books needed in the community, therefore the graduates of Al-Badriyah Islamic Boarding School have a role in religious field in society, and some graduates have successfully established educational institution, this proves that the study of book in Al-Badriyah Islamic Boarding School done well, one way learn kitab turats in this Islamic Boarding School using the Sorogan Method. This study aims to know and analyze: 1). the implementation of Sorogan Method in Al-Badriyah Islamic Boarding School Sundak Rarang East Lombok. 2). the students ability in reading kitab turats by using Sorogan Method at Al-Badriyah Islamic Boarding School Sundak Rarang East Lombok from 2014 until 2017. This research is a case study research using qualitative research approach, that is research which have characteristic that its data is natural phenomenon and oral information. Data collection techniques use observation, interviews, and documentation. Based on the results of the research can be concluded that: 1). The implementation of the Sorogan method is realized with two ways. (a). One student called to go forward to become readers and mean while other friends listening then explained by teacher, all students get turn to progressing to become a reader and not all students get a turn in a meeting of learning but usually the reader 2 to 3 students because of time limitations, while the student who have not got a turn at the learning meeting will get a turn in the next week. The students read the book in his study in front of the teachers then on the sidelines of the reading student sometimes he was asked by his teacher about how to read nahwu and sharafnya, after then teacher give explanation about the discussion at that time. 2). While the ability of students in reading kitab turats with sorogan method is very good and continue to increase because the student continue to get improvements and additional knowledge in reading the kitab turats, but the number of students who follow lesson in particular lesson kitab turats with sorogan method less.
\end{abstract}

Keywords: Sorogan Method, Learning, Kitab Turats.

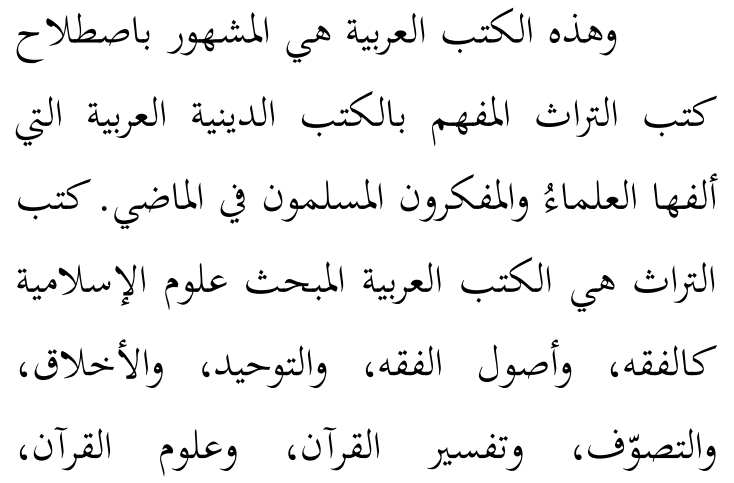

Indonesia, Fakultas Ilmu Pengetahuan Budaya Program Studi Bahasa Arab, Depok 2011), hlm.1

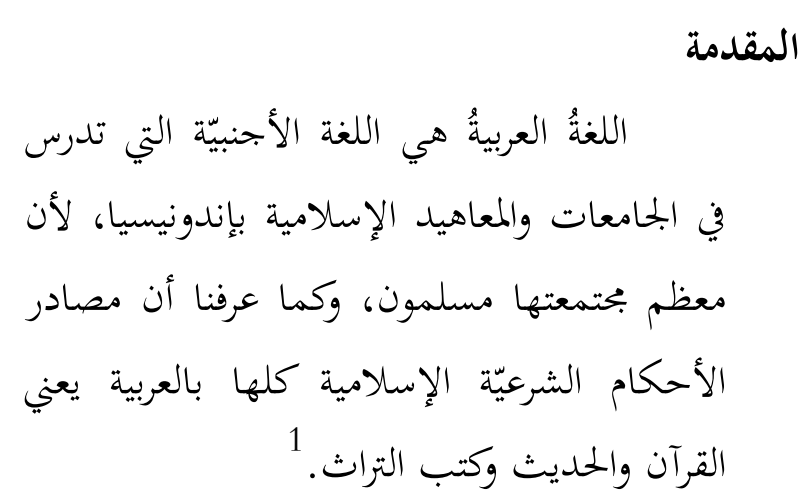

${ }^{1}$ Ahmad Rizki, Metode Pembelajara Bahasa Arab Melalui Media Audiolvisual (Skripsi- Universitas 
وتوجد طريقة التعليم التقليد واستخدمها في

المعاهد والمدارس أو المؤسسات التعليمات. ومن

التقليديّة هي طريقة سوروكان يعني تعليم قراءة

الكتب العربية بالقواعد الأحسن وبارشاد المعلّم.

معهد البدرية الإسلامي هو أحد المعهد العصري

المستخدم طريقة سوروكان فن تعليم كتب التراث.

وقال رئيس المدرسة الدينية في معهد البدرية

(الحاج لالو الأزهر الخالدى البكالوريوس) 7 أنّ ولئ

تعليم كتب التراث في هذا المعهد ثبوت بطريقة

التقليدية منذ أسِّس المعهد في سنة 1407 هـ./

1986 م. حتّى الآن. وطريقة سوروكان هي طريقة

التعليم التي يستعملها بعض المعلّمين في معهد

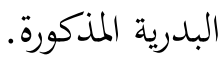

ولوكان التعليمُ فيه بطريقة سوروكان بل إن

يرى كفاءة الطلبة في قراءةكتب التراث فقد حدث

التغيير لهم في سنَوات متأخرات. وقال ذُوالقَرنَنْنِ 8

" مُعَدَّلاً، جميعُ الطلبة الذين أخي الكبير في معهد

البدرية لمم كفاءة في قراءة الكتب. وكفائتهم في

قرائتها في هذه السنوات المتأخرات أقلّ وأدنى، ولو

كانوا يتعلّموا كتب التراث كل يوم. وقد حدث

الأقل والأدنى منذ بنحْتُ في سنة

2013 م. تقريبا. وكفائتهم في الآخَر كنشاط

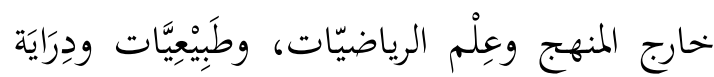

آخَر ظاهر الجليّد حتى الآن". فعُلِم أنّ كفائتهم في

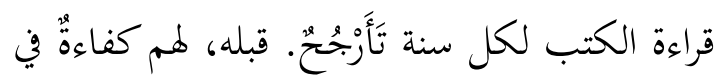

7ملاحظة الباحث (يوم السبت،13 يناير 2018.

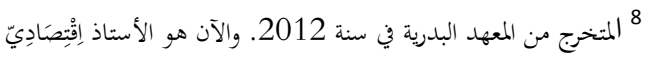

في المدرسة المتوسطة البدرية.
والحديث، وعلوم الحلديث، وغير ذلك، الذي ألفه

العلماء السلفي والخلفي. وتستخدم الكتب بالمادة الرئيسة في المعاهد. 2

إجمالا، استعمل كتب التراث في المعاهد،

خصوصا بالمعاهد التى تثبت طريقة التعليم بصورة

الحلقة. استعمال كتب التراث هي عرفية الْعلوم

الْمُلتصِق في نظام التعليم بالمعهد. وقد بُعلت

كتب التراث لصورة جانبية، ولعُنصُر مفضَّل في

تعليم الإسلام بالمعهد. ولذلك، كوغا ثُميزّة المعهد

لاسيّما فيه السلفي.

أمّا الذي يُتَمَعَّنُ في تعليم اللغة العربية

بتصوير كتب التراث هو طريقة تعليمها. وغالبًا،

استخدام طريقة التعليم هو الحِسْبَةُ من بحاح تعلّم

اللغة أو لا، لأفها تعيين رِلمحتويات والأساليب

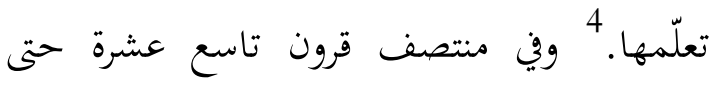

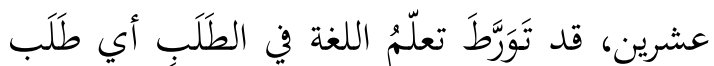

الطريقة التي تُنجح تعليم اللغة الأجنبية في

الفصل. 5 وطريقة التعلّم في اللغة العربية كثيرة، من تعليم

طريقة التقليدية حتى الحديثية. 6

${ }^{2}$ Zubaidi, et. al., Materi Dasar Nahdlatul Ulama (Ahlussunnah Waljamaah), (Semarang: LP.Ma'arif NU Jawa Tengah,2002), hlm. 9

${ }^{3}$ Djamas Nurhayati. Dinamika Pendidikan Islam Di Indonesia Paska kemerdekaan. (PT Raja Grafindo Persada, Jakarta 2009). hlm. 34

${ }^{4}$ Sumardi Muljanto, Pengajaran Bahasa Asing: Sebuah Tinjauan Dan Segi Metodologi, (Jakarta: Bulan Bintang, 1975), hlm.1

${ }^{5}$ Douglas Brown, Perinsip Pembelajaran Dan Pengajaran Bahasa (Edisi Kelima) Penerjemah Noor Cholis Dan Yusi Avianto Pareanom, ( Jakarta: Kedutaan Besar Amerika Serikan 2008, 2001), hlm.14

${ }^{6}$ Fahrurrozi Aziz, Pembelajaran Bahasa Asing: Metode Tradisional Dan Kontemporer (Jakarta: Bina Plishing, 2010), hlm.1 
بمدير المعهد توان كورو الحاج لالو بدرى الطاهر .ويأخذ الباحث هذا المكان لأنّ ذلك المعهد هو الذي يطبّق طريقة سوروكان بالأحسن منذ أُُسِّه حتى الآن، وكفاءة الطلبة الذين يتعلمون فيه هي أفرز عند بحتمعهم، وفي سنوات متأخر يغيّر الطلبة فيه على كفائتهم في قراءة كتب التراث. وأسلوب جمع البيانات فيه هي الملاحظة، والمقابلة، والتوثيق. وقام الباحث الملاحظة بالمشاركة في معهد البدرية ونشاط التعليم فيه. فقد حصل الباحث البيانات عن برامج التعليم فيه، وتطبيق طريقة سوروكان فيه، وكفاءة الطلبة في قرائة كتب التراث بطريقة سوروكان فيه. وقد قام الباحث المقابلة بالأساتذ والطلبة مباشرة في تطبيق طريقة سوروكان وكفاءة الطلبة في قرائة كتب التراث بطريقة

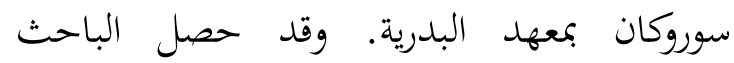
البيانات عن نشاط تعليم كتب التراث بطريقة سوروكان فيه، وكفائة الطلبة في قرائة كتب التراث بطريقة سوروكان فيه. ووي التوثيق، قد طلب الباحث البيانات، فحصل صُوْرَة جَانِيَّة عن مهعد البدرية وأرشيف عن مدير المعهد والأساتذ وما

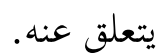 \\ تحليلها ومناقشها}

تطبيق طريقة سوروكان في تعليم كتب التراث

تطبيق طريقة سوروكان في تعليم

كتب التراث بمعهد البدرية هو يُقام في

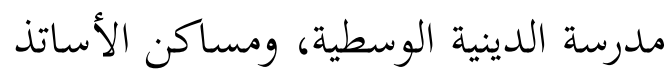
فيه. وإقامة التعليم بطريقة سوروكان في المدرسة الدينية هي في يوم الإثنين بعد
قرائتها. وبعده، كفائتهم فيها إختفاضُ، ولو طريقة التعليم في سنة القادم والحديث متساويّا.

حقيقة، التعليم بطريقة سوروكان هو أحسن

الطريقة على الطلبة ليستطيعون قراءة كتب التراث. وفي الواقع، يستمعون ما يقرأ ويبيّن به المعلم، ثم يستمرون قراءةَ الكتب كما فعله المعلّم تبادُلاً. ولكن لهن كفائتهم في قراءها لحُسبَتت بالناقص. و وينبغي الطريقة الجيّدة أن يطلع أيضا على الكفاءة الجيّدة للطلبة كفي سنوات سابقات. وحين مشهود حاصلهم من اختبارهم هو الناقص. ولذلك، أسئلة البحث في هذا البحث هي: كيف تطبيق طريقة سوروكان في تعليم كتب التراث بمعهد البدرية الإسلامي؟ وكيف كفاءة الطلبة في قرائة كتب التراث بطريقة سوروكان في تعليم كتب التراث بمعهد البدرية الإسلامي.؟ منهجية البحث

استخدم الباحثُ طريقة منهج البحث

الكيفيّ بجنس دراسة الحالة، والباحث هنا هو الأداة الرئيسية، في هذا البحث لأنه عيّن أسئلة البحث.

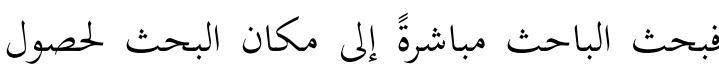
البيانات في تطبيق طريقة سوروكان في تعليم كتب التراث وكفاءة الطلبة في قرائة كتب التراث بها في معهد البدرية سنداك رارنج لومبوك الشرقية، ويُخبّر الباحث نتائجه موافق بالواقع. وكون الباحث هو المعلوم بفاعل الْبَحْث أو بمُخبِره. وأما مكان البحث هو معهد البدرية الإسلامية سنداك رارنج لومبوك الشرقية. بالسّارع معهد البدريّة، ضيعة سنداك، قرية رارنج، منطقة ترارا، مُدِيْرِيَّة لومبوك الشرقية، نوسى تنجرا الغربية. 
يقول إنّ طريقة سوروكان هي إحدى طراز

تعليم التي تتركّز على الطلبة Student . Centered Learning) التعليم ليدفع الطلبة ناشط في إحياء العلوم والسلوك. وفي عملية التعليم التي تركّز على الطلبة فيستفد الفرصة والسهولة ليُنمِي على علومهم. حتى يتركّون الفهم ويرتفعون الكفاءة. 10

ولا يقرأ جميع الطلبة الكتاب في

كل المواجهة ولكن 2 حتى 3 شخص يتراع

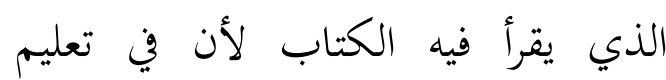

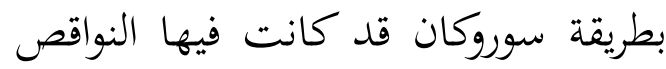

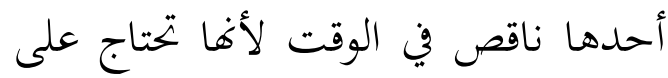

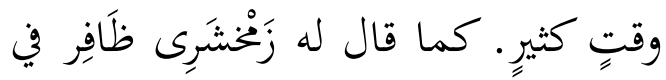

كتابه الموضوع : Tadisi Pesantren Sstudy Tentang Pandangan Hidup يقول أن طريقة سوروكان إذا يُنظًَ من حيث الوقت والمعلّم فليس لها حسنة،

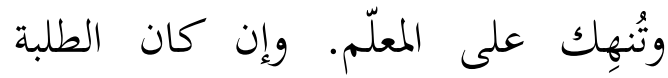
التعليم كثيرًا فيحتاجون على وقت كثير كنير،

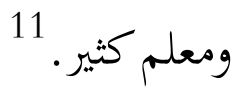

ولذلك، ليوافق الوقت والمعلم في

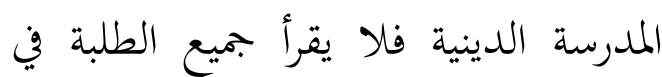

${ }^{10}$ Hamruni, Strategi Pesantren Vs Kapitalisme Sekolah, (Semara ng: NEED ${ }^{\mathrm{ee}}$ S PRES, 2008), hlm.236

${ }^{11}$ Dhafier, Tradisi Pesantren Studi Tentang Pandangan Hidup Kyai,(Jakarta : LP3ES, 1983), hlm. 28
صلاة الصبح جماعة. والمعلّم فيها الأستاذ الحاج حُسَيْن. ويتعلم في فصل الواحد والثاني الوسطية كتاب الأسماوي، ويتعلم أيضا كتاب فتح القريب في يوم الأربعاء بعد صلاة العصرى بالجماعة. وابمعلّم فيها الأستاذ مَروحِي.

وكيفية طريقة سوروكان في تعليم

كتب التراث بمدرسة الدينية الوسطية هي

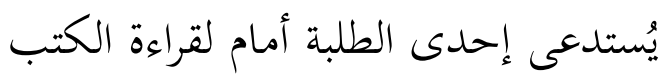

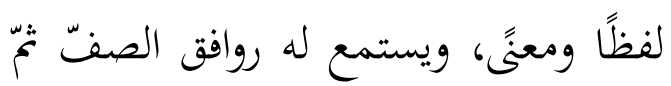
يشرح الأستاذ ما قرأ له. وكل الطلبة يقرأ الكتب أمام متبادلا. ويقرأ في مواجهة توفّق الأمر على الوقت. ولكن عادة 2 حتى 3 قارئ الكتب في كل المواجهة. وأداء طريقة سوروكان في مدرسة الدينية موافق بشرح وحيو أوتومو الذي نقل له أ.عارف يقول أنّ طريقة سوروكان هي النظام في التعليم، يتقدم الطلبة واحدا

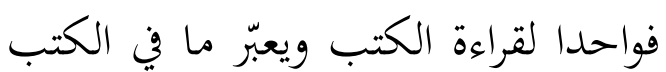
أو القرآن أمام المعلم أو كياهي. وطريقة سوروكان في المدرسة الدينية تدفع الطلبةَ لنشاط ودوام في تعليم كتب Strategi التراث وكما قال حمروين في كتابه Pesantren Vs Kapitalisme Sekolah

${ }^{9}$ Arief Armai, 2002, Pengantar Ilmu dan Metodologi Pendidikan Islam, Ciputat: Ciputat Press, hlm. 150 
قراءته قد يسأل الأستاذ عن قراءته من

النحو والصرف والمراد عن نصوص مقروء.

وإن يقرأ الطالب خطأ فيصلح الأستاذ

عليه مباشرة، ثمّ يشرح الأستاذ على ما قرأ

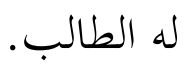

وأداء التعليم بطريقة سوروكان في

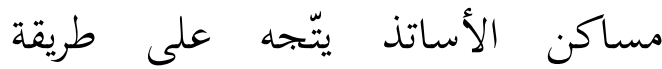

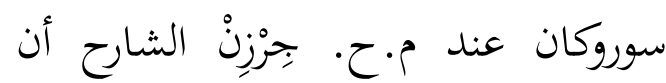

طريقة سوروكان هي يواجه الطلبة واحدا

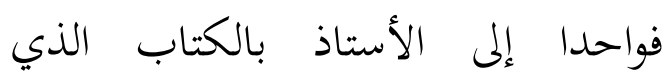

$$
\text { يتعلمون له. } 13
$$

وحين التعليم، يقرأ الطلبة الكتب

لفظا ومعنى. وقد يسأل الأستاذ في القراءة

من النحو والصرف ومراد نصّ المقروء،

لماذا يفعل الأستاذ على ذلك، لأن يقصد

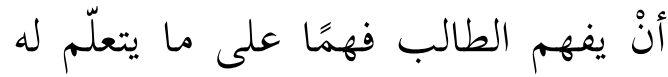

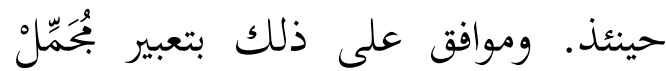

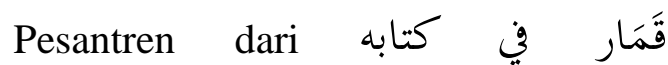

Metodologi Transformasi

سوروكان يفضّل على فهم شخص

$$
\text { واكتراثه مع كفاءته. } 14
$$

\section{كفائة الطلبة في قراءة الكنب التراث}

${ }^{13}$ Chirzin, Agama, Ilmu, dan pesantren, dalam Dawam Raharjo, Pesantren dan Pembaruan, (Jakarta: LP3ES, 1985), hlm.88

${ }^{14}$ Mujamil Qomar, Pesantren: Dari Transformasi Metodologi Menuju Demokratisasi Institusi (Bandung: Erlangga, 2007), Cet.III, hlm.145
كل مواجهة أمام. ويكفى 2 حتى 3

قارئ في المواجهة ولكن الطالب الذي لم

يقرأ فيها فسوف يقرأ الكتاب في المادة

$$
\text { والمواجهة الآتية. }
$$

التعليم كتب التراث بطريقة

سوروكان هو يفعل لها أيضا الطلبةُ التعليم

في الأساتذ الذين يسكنون في مهرد بهد

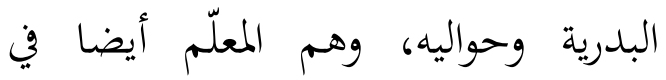

المدرسة الدينية معهد البدرية. التعليم في

الأساتذ هو يقوم عليه الطلبة في اليل بعد

صلاة العشاء جماعة. ويتعلمون فيها

الكتاب متن الآجرومية وشرحها،

وأسماوي، وفتح القريب، وأنوار المسالك.

ما حدث في هذا معهد البدرية

مناسب بما عبر له نُوْرَحَلِص بَحِيد في

كتبه:Bilik-bilik Pesantren

بطريقة سوروكان هو طلب شخص أو

أشخاص أي الطلبة إلى كياهي أو الأستاذ

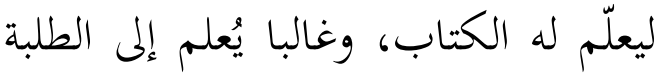

النشاط والجادّ والراكز للعالم أو كياهي. 12

وأداء التعليم بسوروكان في مساكن

الأساتذ هو يجيء الطلبة بالكتاب إلى

منزلة الأستاذ، وحين التعليم يقرأ الطالب لتبائ

واحد فواحد، ويستمع قراءتَه روافقُه، ومع لعرانع

${ }^{12}$ Madjid, Nurcholish. Bilik-Bilik Pesantren, Sebuah Potret Perjalanan. (Jakarta: Paramadina1997) hlm 28 
وإن يرى من ذلك، فيذكر الطلبة في

معهد البدرية بكفاءة القراءة لأهم

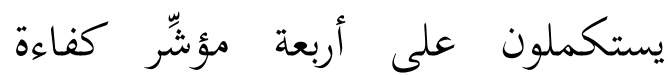
القراءة. وقد قدروا الطلبة معهد البدرية ليلفظون جملة الكلمة أو الكلمِم في معرداء الكتاب، وليعترفون الإعراب، وليترجمون كتب التراث، وليشرحون ما يشمل في كتب التراث لأن يقرؤوا الكتاب المتعلم ويرتجموا إلى اللغة الإندونيسي، ويُسألون في النحو والصرف، وقبل يشرح المعلم فقد يشرحون على مراد ما قرؤوا له ثم يكرّر المعلم عن شرحهم. وكفاءة الطلبة في قراءة كتب التراث بطريقة سوروكان منذ سنة 2014 حتى 2017 هي الجيّد يعنى يقدرون في قراءة كتب التراث بالجيد ويرتفع كفاءهم دائما. ولكن كما يُعتبرَ في المبحث السابق

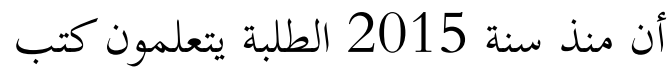
التراث بسوروكان أقلّ حتى الآن. ولذلك، لته الطلبة الكفاءة في قراءة كتب التراث

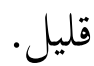

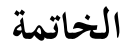
الحاصل في هذا البحث هو: 1- تطبيق طريقة سوروكان في تعليم كتب التراث بمعهد البدرية الإسلامي سنداك رارنج لومبوك الشرقية هو في حالتين، وهما:
كفاءة الطلبة بمعهد البدرية في قراءة

كتب التراث بطريقة سوروكان خلافُ عن الطلبة الذين لايتعلمون بطريقة سوروكان. والطلبة التي تتعلم هما هي الطلبة النشاط والجادّ والواظف يتعلّمون في معهد البدرية. وتعليم كتب التراث بطريقة سوروكان في معهد البدرية قد تأثر على ارتفاع كفاءة الطلبة في قراءة كتب التراث. وكما قال له ساعد عاقل سراج في تراءه

كتابه الموضوع Pesantren Masa Depan يقول أن الفاضل من التعليم بطريقة سوروكان في المعهد سيتكفّل على كفاءة الشخص، لأن كل الطلبة يكملون على لئل برنامج تعليمهم بكفاءقم. وبذلك لن يتأخر كفاءةم بمتأخر الطالب الآخر. 15

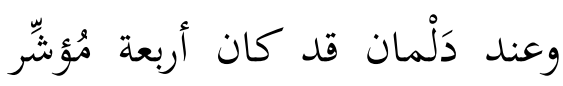
الكفاءة في قراءة كتب التراث، يعنى: 1. كفاءة ليلفظ جملة الكلمة أو الكلِم

$$
\text { 3. } 3 \text { 3. كفاءة ليعترف الإعراب كفاءة ليترجم كتب التراث }
$$

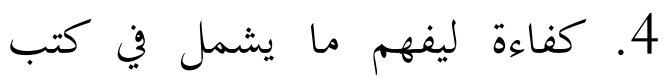

$$
\text { التراث. } 16
$$

${ }^{15}$ Aqiel Siradj Saeid et.al., Pesantren Masa Depan, (Bandung: Pustaka Hidayah, 1999), hlm. 281

${ }^{16}$ Dalman, Keterampilan Membaca, Jakarta: Pt Grafindo Persada,2013). hlm.5 
حتى 2018 هي الجيد، لأن الطلبة ينالون

في كل تعليمهم تحسينَ العلوم وزيادتَه عن

قراءة كتب التراث حتى يستكملون أربعة

مُمََِّّّر مهارة قراءة كتب التراث يعنى قادر

ليلفظ الكلمات المقروء، وقادر لمعرفة

الإعراب، وقادر ليترجمها، وقادر ليفهم

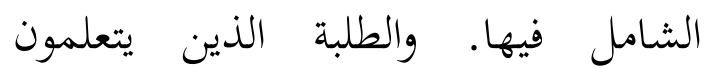

بسوروكان فقد قدر عليهم قراءة الكتب

بالجيد. ولكنهم الذين يتعلمون بها قليل.

$$
\text { قائمة المراجع والمصادر }
$$

Arief, Armai, 2002, Pengantar Ilmu dan Metodologi Pendidikan Islam, Ciputat: Ciputat Press.

Aziz, Fahrurrozi, 2010, Pembelajaran Bahasa Asing: Metode Tradisional Dan Kontemporer, Jakarta: Bina Plishing.

Brown, Douglas, 2001, Perinsip Pembelajaran Dan Pengajaran Bahasa (Edisi Kelima) Penerjemah Noor Cholis Dan Yusi Avianto Pareanom, ( Jakarta: Kedutaan Besar Amerika Serikan 2008.

Chirzin, 1985, Agama, Ilmu, dan pesantren, dalam M. Dawam Raharjo, Pesantren dan Pembaruan, Jakarta: LP3E.

Dalman, 2013, Keterampilan Membaca, Jakarta: Pt Grafindo Persada.

Dhafier, Zamkhasyary, 1983, Tradisi Pesantren Studi Tentang Pandangan Hidup Kyai, Jakarta : LP3ES.

Djamas, Nurhayati, 2009, Dinamika Pendidikan Islam Di Indonesia Paska kemerdekaan. Jakarta: PT Raja Grafindo Persada.

Hamruni, 2008, Strategi Pesantren Vs Kapitalisme Sekolah, Semarang: NEED"es PRES.

Madjid, Nour Cholis, 1997, Bilik-Bilik Pesantren, Sebuah Potret Perjalanan, Jakarta: Paramadina.

$$
\text { أ- في مدرسة الدينية الوسطية }
$$

أداء طريقة سوروكان في مدرسة

الدينية هو في يوم الإثنين بعد صلاة

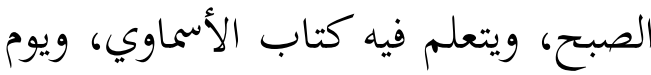

الأربعاء بعد صلاة العصر، ويتعلم فيه ويعم لـيه

فتح القريب. وكيفية تطبيقها هي

يُستدعى أحد الطلبة لتقليم ولقراءة

الكتاب لفظا ومعنى، ويستمع له روافق

الصفّ، ثم يشرح الأستاذ على ما قرأ له.

ويقرأ كل الطلبة الكتابَ، ولا يقرأ الكتابَ لهن

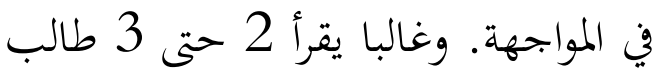

في المواجهة لأن الوقت قِصرٌ. . وسوف يقرأ

$$
\text { الآخر الكتابَ في المواجهة الآتية. }
$$$$
\text { ب- في مساكن أساتذ معهد البدرية }
$$

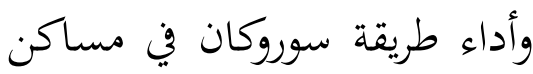

الأساتذ هو بعد صلاة العشاء بالجماعة

ويتعلم فيه متن الأجرومية وشرحها،

والأسماوي، وفتح القريب، وأنوار

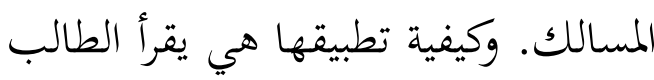

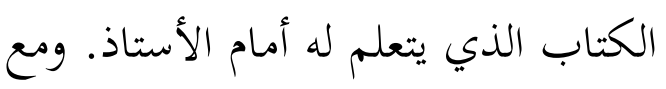

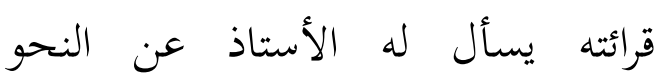

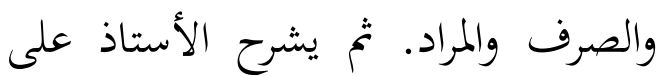

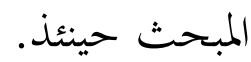

2- كفاءة الطلبة في قرائة كتب التراث بطريقة

سوروكان بمعهد البدرية الإسلامي سنداك

رارنج لومبوك الشرقية. منذ سنة 2014 
Zubaidi, 2002, Materi Dasar Nahdlatul Ulama (Ahlussunnah Waljamaah), Semarang: LP.Ma'arif NU Jawa Tengah.

Rizki Ahmad, 2011, Metode Pembelajara Bahasa Arab Melalui Media Audiolvisual, Skripsi- Universitas Indonesia, Fakultas Ilmu Pengetahuan Budaya Program Studi Bahasa Arab, Depok.
Qamar, Mujamil, t.th. Pesantren dari Transformasi Metodologi Menuju Demokratisasi Institusi, Jakarta: Erlangga.

Siradj, Sa'id Aqiel, 1999, Pesantren Masa Depan, Bandung: Pustaka Hidayah.

Sumardi, Muljanto, 1975, Pengajaran Bahasa Asing: Sebuah Tinjauan Dan Segi Metodologi, Jakarta: Bulan Bintang. 